\title{
A Gestão Social a Partir do Olhar Crítico da Sociologia das Ausências e da Sociologia das Emergências de Boaventura \\ de Sousa Santos
}

\section{Social Management from a Critical View of the Sociology of Absences and Sociology of Emergences (Boaventura de \\ Santos Sousa)}

\author{
Raphaela Reis Conceição Castro Silva \\ Doutoranda em Administração. Universidade Federal de Santa Catarina, Brasil, castroreis@gmail.com \\ http://lattes.cnpq.br/2751499099289877 \\ Luis Moretto Neto \\ Doutorado em Engenharia de Produção. Professor do Centro Universitário Internacional, Brasil, luis.moretto.neto@ufsc.br \\ http://lattes.cnpq.br/5353000298059913
}

Resumo: Este artigo pretende investigar os estudos sobre Gestão Social no Brasil, campo ainda em formação. Para tanto, busca-se, por meio da perspectiva da sociologia das ausências e da sociologia das emergências, proceder a uma análise da produção acadêmica brasileira sobre Gestão Social, a fim de refletir se esses estudos abordam práticas sociais emergentes no sentido adotado por Boaventura de Sousa Santos. O objetivo deste trabalho é proporcionar, portanto, um alargamento teórico aos estudos sobre a Gestão Social a respeito de alternativas na produção desse campo em construção.

Palavras-chave: gestão social; sociologia das ausências; sociologia das emergências.

Abstract: This article aims to investigate the studies of Social Management in Brazil, a field still in formation. Therefore, we seek, through the perspective of the sociology of absences and the sociology of emergences, to carry out an analysis of the Brazilian academic production on Social Management, to reflect whether these studies address emerging social practices in the sense proposed by Boaventura de Sousa Santos. The objective of this study is to provide a theoretical extension to studies on Social Management regarding alternatives in the production of this construction in the area.

Keywords: social management; sociology of absences; sociology of emergences.

Texto completo em português: http://www.apgs.ufv.br Full text in Portuguese: http://www.apgs.ufv.br

\section{Introdução}

Diante de muitas discussões no campo dos estudos organizacionais, é possível identificar que o sistema de mercado, pautado pela racionalidade instrumental, está solapando os demais sistemas sociais, os quais, teoricamente, deveriam estar pautados por outras formas de racionalidade. Nesse sentido, a sociedade contemporânea passa por um processo de unidimensionalização, no qual o enclave econômico acaba por influenciar e definir os demais enclaves necessários para a autorrealização dos indivíduos.

Guerreiro Ramos (1989), na abordagem orientada para a delimitação de sistemas, tece críticas referentes à razão moderna e, consequentemente, à sua influência sobre a vida humana associada e às discussões das ciências sociais. Nesse sentido, Guerreiro Ramos (1989) ressalta que a razão substantiva é um atributo natural do sujeito que reside na psique humana. Com base nessa razão, os indivíduos poderiam ordenar a sua vida pessoal na direção da autorrealização, levando em conta o direito dos demais indivíduos de também poderem buscá-la. Para o autor, o caminho para esse equilíbrio seria o debate racional e o julgamento ético-moral permanente das ações.

Com a finalidade de aprofundar o tema, apresenta-se o trabalho de Boaventura de Sousa Santos (2002) sobre alternativas à globalização neoliberal que emerge do pensamento hegemônico, a partir de experiências concretas de sociabilidade sobre as quais questiona a razão indolente (modelo de razão ocidental) e evidencia a necessidade da elaboração de uma teoria que traga à tona a impossibilidade de uma teoria geral. Tendo como pressupostos a ideia de que a compreensão de mundo suplanta a visão ocidental e que a razão indolente comprime o presente entre o passado e futuro, Santos (2002) propõe a razão cosmopolita, que possibilita superar as limitações da razão dominante. $\mathrm{O}$ autor afirma que a razão cosmopolita se apoia em três procedimentos sociológicos: a sociologia das ausências, a sociologia das emergências e o trabalho de tradução.

Correspondência/Correspondence: Raphaela Reis Conceicao Castro Silva. Universidade Federal de Santa Catarina. R. Eng. Agronômico Andrei Cristian Ferreira, s/n - Trindade, Florianópolis - SC, 88040-900. 
Com base nessas reflexões, busca-se analisar, por meio da perspectiva da sociologia das ausências e da sociologia das emergências, a produção acadêmica brasileira sobre o campo da Gestão Social,com o propósito de refletir se esses estudos abordam práticas sociais emergentes no sentido adotado por Boaventura de Sousa Santos.

Assim, a importância deste estudo é proporcionar um alargamento teórico e prático aos Estudos Organizacionais a respeito de alternativas na produção desse campo em construção. De acordo com Caldas e Fachin (2005), Vergara e Caldas (2005) e Caldas e Cunha (2005), a grande maioria das pesquisas desenvolvidas no campo da administração ainda apresenta métodos tradicionais de orientação positivista e funcionalista. Assim, a Gestão Social propõe dar visibilidade a movimentos da sociedade civil, em uma perspectiva que se distancie da abordagem dominante e gerencialista de gestão. Dessa maneira, a intenção deste trabalho é analisar a produção acadêmica sobre Gestão Social, não perdendo de vista sua intenção e proposta, por meio das ecologias defendidas por Santos (2002) em seus estudos, sendo elas a ecologia dos saberes, a ecologia das temporalidades, a ecologia dos reconhecimentos, a ecologia das trans-escalas e a ecologia de produtividade.

Nesse sentido, a fim de viabilizar esta pesquisa, pretende-se analisar, dentro do espaço hegemônico da administração, a produção acadêmica em estudos organizacionais no periódico nacional Cadernos EBAPE do Vol. IX, no. 3 (2011):"Gestão Social: Ensino, Pesquisa e Prática", no qual foram publicados onze artigos sobre a temática. Essa revista está classificada no sistema Qualis da Capes como B1.

\section{Referencial Teórico}

\subsection{Gestão social e seus discursos}

A Gestão Social vem-se apresentando como campo promissor de desenvolvimento dos estudos organizacionais. $O$ tema emergiu como uma possibilidade inovadora de pesquisa e ensino no campo da Administração. Existem diversos pesquisadores no Brasil que, desde a década de 1990,vêm-se dedicando à temática, e, principalmente a partir da segunda metade da primeira década deste século, com a criação de programas de pesquisa, surgiram encontros especializados e mesmo periódicos dedicados ao tema. Institucionalizada em 2003, a Rede Brasileira de Pesquisadores em Gestão Social (RGS) é formada pelos diversos pesquisadores e grupos de pesquisa instalados em Instituições de Ensino Superior (IES) públicas, privadas e do Terceiro Setor.

Diante desse crescimento e expansão no meio acadêmico e para além dele, há uma diversidade de aplicações e significados atribuídos ao termo Gestão Social (ARAúJO, 2012). Nessa perspectiva, é imprescindível a organização de seu significado e de seus fundamentos teóricos. Japiassu (1991) considera que questionar sobre a história das ciências consiste em indagar sobre sua finalidade, sobre seu destino, sobre seu porquê, mas também sobre aquilo pelo que ela se interessa, de que ela se ocupa, em conformidade com aquilo a que ela visa.

Dessa forma, o objetivo desta seção é apresentar os fundamentos teóricos de delimitação do campo de conhecimento científico da Gestão Social. Para tanto, propõe-se a identificação das correntes de pensamento em Gestão Social que a sustentam como uma área do conhecimento científico.

Paes de Paula (2005) propõe uma aproximação da Gestão Social com a Gestão Pública no sentido da construção de uma Administração Pública Societal e destaca que ainda há um longo caminho a ser trilhado para solidificar essa proposta. A Gestão Social desponta como mais uma possibilidade teórica e prática de gestão. Daí reside a importância de delimitar o campo, visando evitar a vulgarização. Cançado (2011) afirma que a Gestão Social se desenvolve no âmbito da esfera pública, na qual se sobressaem as organizações públicas não estatais e o interesse público da sociedade, além de proporcionar condições à emancipação dos indivíduos baseando-se na democracia deliberativa, na formação da consciência crítica de seres humanos, em uma perspectiva dialógica negativa, sem pretensão de síntese.

Entretanto, observa-se que há uma tendência à banalização do termo, pois "tudo que não é gestão tradicional passa então a ser visto como Gestão Social" (FRANÇA FILHO, 2008, p. 26). Além disso, percebe-se que o termo carece de maior precisão conceitual, possibilitando múltiplas interpretações. Araújo (2012) coaduna com as ideias supracitadas ao afirmar que "a popularização do termo caminhou para uma certa trivialidade, com múltiplos focos de atuação, onde tudo que era relacionado ao campo de expressões da questão social passava a ser gestão social" (p. 37).

Não foi possível encontrar na bibliografia pesquisada as origens da terminologia Gestão Social. A principal pista vem dos textos do professor Tenório, que, desde 1990, atua como coordenador do Programa de Estudos em Gestão Social, vinculado à Escola Brasileira de Administração Pública e de Empresas da Fundação Getúlio Vargas (PEGS/EBAPE/FGV). Conforme Cançado (2011), o primeiro contato de Tenório com o termo foi em um texto de Giorgio Rovida, que trata de experiências autogestionárias na guerra civil espanhola.

Conforme Cançado (2011), o primeiro texto nacional que trata da temática da Gestão Social foi publicado por Tenório em 1998, na Revista de Administração Pública, intitulado "Gestão Social: uma perspectiva conceitual”. Nesse artigo, Tenório (1998) apresenta a base conceitual da Gestão Social, detalhando que trata-se de um produto de experiências teóricas e práticas desenvolvidas no Programa de Estudos em Gestão Social (PEGS), materializado por meio de estudos, da publicação de livros e de atividades de treinamento e cooperação técnica.

Diferente disso, Araújo (2012) aponta que um dos marcos institucionalizadores da Gestão Social foram as práticas de formação e projetos de extensão desenvolvidos na Universidade Federal da Bahia (UFBA), a partir de 2001, no âmbito do 
Programa de Desenvolvimento e Gestão Social (PDGS), implementado pelo Núcleo de Estudos em Poder e Organizações Locais (Nepol) da Escola de Administração (EA). O Nepol, desde 1986 coordenado pela Profa. Tânia Fischer, atuou como um dos mais fortes grupos de pesquisa sobre temas correlatos e que deram origem à ideia de Gestão Social.

A abordagem de Tenório (2008) parte de uma reflexão relacionada ao pragmatismo, ao sucesso do mercado da Administração, decorrente da leitura da obra de Guerreiro Ramos. Segundo Tenório (2008), a Gestão Social poderia ser considerada como uma linha alternativa em relação à hegemonia da tradição positivista centrada na racionalidade utilitária das ciências duras. O autor, baseado em Guerreiro Ramos, na Escola de Frankfurt e, posteriormente, na "segunda geração" da escola alemã com Jürgen Habermas, define os elementos estruturantes da Gestão Social.

A construção do conceito acontece, inicialmente, pela ênfase na importância da sociedade e do trabalho como protagonistas das relações com o Estado e o capital. Tenório (1998) propõe essa mudança de enfoque a fim de destacar a protagonista no processo dessas relações: a cidadania. Em outros termos, Tenório (1998) acentua o papel central que a sociedade civil organizada deve representar perante o mercado. Para tanto, o autor propõe que a cidadania deliberativa intermediei essa relação, o que significa "que a legitimidade das decisões deve ter origem em processos de discussão orientados pelos princípios da inclusão, do pluralismo, da igualdade participativa, da autonomia e do bem comum" (TENÓRIO, 2008, p.16). Tenório (1998, p. 19) esclarece que tal conceito deve ser entendido como uma "ação política deliberativa", na qual o indivíduo deve participar de um procedimento democrático nas diferentes instâncias da sociedade e em diferentes papéis.

Outro fundamento essencial para a construção do conceito de Gestão Social de Tenório é a ação social do tipo comunicativa de Habermas. Assim, no âmbito da Gestão Social orientada pela racionalidade comunicativa, os atores, ao fazerem suas propostas, não podem impor seus objetivos sem que haja um acordo atingido pela via da comunicação (TENÓRIO, 1998). Para o autor, a Gestão Social baseia-se no entendimento estreitamente vinculado à linguagem -, pois, no processo de Gestão Social, o acordo alcançado entre os atores é decorrente de uma discussão crítica. Assim, para Tenório (1998, p.158), a Gestão Social é entendida

Como processo gerencial dialógico em que a autoridade decisória é compartilhada entre os participantes da ação (ação que possa ocorrer em qualquer tipo de sistema social - público, privado ou de organizações nãogovernamentais). $\mathrm{O}$ adjetivo social qualificando $\mathrm{O}$ substantivo gestão será entendido como o espaço privilegiado de relações sociais no qual todos têm o direito à fala, sem nenhum tipo de coação.

Como o objetivo central deste trabalho guarda relação com esses questionamentos, cabe situar as categorias e referências centrais sobre as quais se assenta a noção de razão moderna e, consequentemente, a sua influência sobre a vida humana associada e as discussões das ciências sociais, para se discutir mais apropriadamente a produção científica sobre a temática de Gestão Social.

\subsection{Para uma sociologia das ausências e uma sociologia das emergências}

Santos (2002) tece uma crítica ao modelo de racionalidade ocidental - que ele chama de modelo de uma razão indolente - e propõe um outro modelo baseado na razão cosmopolita. Fundamenta-se em três procedimentos sociológicos nessa razão cosmopolita: a sociologia das ausências, a sociologia das emergências e o trabalho de tradução.

Tal proposta é produto de uma reflexão epistemológica profunda decorrente do estudo realizado em seis países, sendo eles: Moçambique, África do Sul, Brasil, Colômbia, Portugal e Índia. O objetivo desse estudo foi verificar como os movimentos sociais e as organizações não-governamentais lutam contra a exclusão e a discriminação oriundas do capitalismo global e da globalização neoliberal. Esse objetivo converge com a busca do campo da gestão social, que se instaura como um campo de conhecimento e prática da emancipação do homem.Mesmo diante de visões opostas quanto a modernidade. Por um lado, a gestão social, ancorada na argumentação em Habermas, cuja defesa é de um projeto inacabado da modernidade; por outro, Boaventura de Sousa Santos, um crítico ferrenho da modernidade e suas insuficiências.

A reflexão de Santos (2002) baseia-se na ideia de que a ciência social tal como a conhecemos não serve para explicar as experiências sociais que acontecem nesses países e alerta que não basta a proposição de outro tipo de ciência social, mas sim de um modelo diferente de racionalidade. $O$ ponto de partida de Santos (2002) é a sua perplexidade diante da concepção de tempo, da temporalidade e da fugacidade do presente.

Dessa forma, a racionalidade cosmopolita proposta busca seguir a trajetória inversa da indolente, qual seja, "expandir o presente e contrair o futuro" (p. 240), para assim evitar o que Santos (2002) considera um desperdício da experiência ao ignorar a grande riqueza advinda das experiências sociais.

Para expandir o presente, proponho uma sociologia das ausências; para contrair o futuro, uma sociologia das emergências. Dada que a imensa diversidade de experiências sociais revelada por estes processos não pode ser explicada adequadamente por uma teoria geral. Em vez de uma teoria geral, proponho uma teoria de tradução, capaz de criar a inteligibilidade mútua entre experiências possíveis e disponíveis (p. 240).

A razão indolente desenvolveu-se no contexto sociopolítico das revoluções industriais e do desenvolvimento do capitalismo. Dessa forma, a razão indolente está presente no conhecimento hegemônico, tanto filosófico quanto científico, produzido no ocidente nos últimos duzentos anos. A razão indolente criticada por Santos (2002) se dá de quatro formas: 
1. A razão impotente: aquela que não se exerce porque pensa que nada pode fazer contra uma necessidade concebida como exterior a ela própria;

2. A razão arrogante: não sente necessidade de se exercer porque se imagina incondicionalmente livre;

3. A razão metonímica: reivindica-se como a única forma de racionalidade e, assim, não se aplica a descobrir outros tipos de racionalidade;

4. A razão proléptica: não se aplica a pensar o futuro porque julga que sabe tudo a respeito dele.

A primeira, a razão metonímica, defende a ideia da totalidade sob a forma da ordem. "As possíveis variações do movimento das partes não afetam o todo e são vistas como particularidades. A forma mais acabada de totalidade para a razão metonímica é a dicotomia, porque combina a simetria com a hierarquia" (SANTOS, 2002, p. 242). A razão metonímica afirma-se como uma razão exaustiva, exclusiva e completa, muito embora seja apenas uma das lógicas de racionalidade que existe no mundo e dominante apenas nos estratos do mundo abrangidos pela modernidade ocidental. A compreensão do mundo por essa lente é parcial e muito seletiva. A modernidade ocidental, dominada por essa razão, tem uma compreensão limitada do mundo e de si própria (SANTOS, 2002). Portanto, para que seja possível a ampliação do presente, a crítica à razão metonímica é uma condição necessária.

Santos (2002) apresenta uma proposta para repensar a razão metonímica: (1) proliferação das totalidades, ou seja, fazê-la coexistir com outras totalidades; (2) mostrar que qualquer totalidade é feita de heterogeneidade e que as partes que a compõem têm uma vida própria fora dela. Parafraseando Santos (2002), é preciso pensar o sul como se não houvesse o norte, pensar a mulher como se não houvesse o homem.

Para o autor, a razão metonímica é ainda dominante e, para que a proposta de ampliação do presente se efetive, é preciso começar por um procedimento designado por ele como sociologia da ausências, a fim de perceber as partes independentes da totalidade. Ademais, faz-se necessário romper com as ciências sociais convencionais.

Trata-se de uma investigação que visa demonstrar que o que não existe é, na verdade, ativamente produzido como tal, isto é, como uma alternativa não-credível ao que existe. O objetivo da sociologia das ausências é transformar objetos impossíveis em possíveis e com base neles transformar as ausências em presenças" (p. 248).

Santos (2002) aponta cinco lógicas ou modos de produção da não existência legitimadas pela razão metonímica. Em outras palavras, cinco principais formas sociais excluídas, marginalizadas, a saber: o ignorante, o residual, o inferior, o local e o improdutivo. "Trata-se de formas sociais de inexistência porque as realidades que elas conformam estão apenas presentes como obstáculos em relação às realidades que contam como importantes, sejam elas realidades científicas, avançadas, superiores, globais ou produtivas" (p. 251). A sociologia das ausências visa identificar o âmbito dessa subtração de modo que as experiências produzidas como ausentes sejam libertadas e se tornem presentes. "Tornar-se presente significa serem consideradas alternativas às experiências hegemônicas, a sua credibilidade poder ser discutida e argumentada e as suas relações com as experiências hegemônicas poderem ser objeto de disputa política" (p. 252).

Para que a sociologia das ausências seja possível, essas lógicas devem ser substituídas por cinco lógicas que Santos (2002) denomina de ecologias, as quais evidenciam que a realidade não pode ser reduzida ao que existe, a saber: a lógica da monocultura do saber deve ser substituída pela ecologia dos saberes, baseada na ideia de que os saberes não científicos são alternativos ao saber científico; a lógica da monocultura do tempo linear deve ser substituída pela ecologia das temporalidades, em que as práticas sociais são libertadas de seu estatuto de resíduo, restituindo-Ihes a temporalidade própria; a lógica da classificação social deve ser substituída pela ecologia dos reconhecimentos, visto que as diferenças que subsistem quando desaparece a hierarquia tornam-se uma denúncia poderosa das diferenças que a hierarquia exige para não desaparecer; a lógica da escala global deve ser substituída pela ecologia das trans-escalas e recuperação daquilo que, no local, não é efeito da globalização hegemônica; e a lógica produtivista deve ser substituída pela ecologia da produtividade, que consiste na recuperação e valorização dos sistemas alternativos das organizações econômicas populares que a ortodoxia capitalista descredibilizou (SANTOS, 2002).

A segunda análise realizada por Santos (2002) tece uma crítica sobre a razão proléptica. A crítica proléptica é uma das faces da razão indolente, quando contrai o presente e dilata enormemente o futuro.Enquanto a crítica da razão metonímica tem por objetivo dilatar o presente, a crítica da razão proléptica tem por objetivo contrair o futuro. "Contrair o futuro significa tornálo escasso, e como tal, objeto de cuidado" (SANTOS, 2002, p. 257).

Enquanto a dilatação do presente é obtida por meio da sociologia das ausências, a contração do futuro é obtida pela sociologia das emergências, baseada na investigação das possibilidades plurais e concretas. A sociologia das emergências implica a ampliação de práticas e saberes da sociologia das ausências, para, desse modo, vislumbrar alternativas futuras. As duas sociologias estão interligadas, visto que "quanto mais experiências estiverem hoje disponíveis no mundo, mais experiências são possíveis no futuro" (p. 263).

$\mathrm{Na}$ sociologia das ausências, a multiplicidade e diversidade das experiências ocorre por meio da ecologia dos saberes, dos tempos, das diferenças, das escalas e das produções. $\mathrm{Na}$ sociologia das emergências, por meio da amplificação simbólica das pistas ou sinais. Nessa direção, os principais campos sociais nos quais a multiplicidade pode ser identificada são: experiências de conhecimento, experiências de desenvolvimento, experiências de reconhecimento, experiências de democracia, experiências de comunicação e de informação (SANTOS, 2002).

Sobre tal multiplicidade e diversidade das experiências, Santos (2002) levanta dois problemas complexos. Primeiro, o 
problema da extrema fragmentação, e o segundo, como consequência do primeiro, o problema da impossibilidade de conferir sentido à transformação social.Do ponto de vista da razão cosmopolita - razão conceituada pelo referido autor -, Santos (2002) propõe o trabalho de tradução aos problemas acima, que consiste em criar inteligibilidade recíproca entre as experiências múltiplas reveladas pelas duas sociologias.

A tese defendida por Santos (2002) é da sociologia das ausências e da sociologia das emergências juntamente com o trabalho de tradução, para desenvolver uma razão alternativa à indolente, a razão cosmopolita.Santos (2002) acrescenta que a utilização de sua teoria não garante a resolução de tais problemas: "não há garantia de que o mundo melhor seja possível e muito menos de que todos os que não desistiram de lutar por ele o concebam do mesmo modo" (p. 280).

\section{Procedimentos Metodológicos}

Este estudo caracteriza-se como uma estratégia de pesquisa teórico-empírica e baseou-se em artigos científicos publicados no periódico nacional, classificado pela Capes, Cadernos EBAPE. Optou-se por analisar a edição especial intitulada "Gestão Social: Ensino, Pesquisa e Prática". A referida edição foi publicada em 2011 e contou com a contribuição de onze artigos sobre a temática,escritos por diversos pesquisadores latino-americanos $A$ seleção dessa edição deu-se por compreender que suas publicações influenciam fortemente a composição do campo da Gestão Social, que encontra-se em construção, e há uma confusão generalizada entre os pesquisadores que contribuem para a constituição desse campo. Ademais, trata-se de uma revista classificada no sistema Qualis da Capes como B1, portanto, de grande prestígio.

Assim, tendo em vista garantir uma compreensão mais ampla do que Boaventura chamou de sociologia das ausências e sociologia das emergências, baseou-se nas ideias por ele desenvolvidas para estudar as alternativas à globalização neoliberal e ao capitalismo global produzidas por outras experiências, na sua luta contra a exclusão e a discriminação em diferentes domínios sociais e em diferentes países.

Adotaram-se dois procedimentos iniciais de análise. 0 primeiro caracteriza-se pela identificação de iniciativas, movimentos experiências em cinco (5) áreas temáticas em que mais claramente se condensam os conflitos, conforme aponta Santos (2002), a saber: democracia participativa, sistemas de produção alternativos e economia solidária; multiculturalismo, direitos coletivos, pluralismo jurídico, cidadania cultural; alternativas aos direitos de propriedade intelectual e biodiversidade capitalistas; e novo internacionalismo operário. Posteriormente, por meio da análise de conteúdo, buscou-se, neste trabalho, o reconhecimento das chamadas ecologias: dos saberes, das temporalidades, do reconhecimento, das escalas locais e globais e das produtividades.

\section{Análise dos Trabalhados Selecionados}

Para esta pesquisa foram analisados onze artigos da área de Administração publicados no Cadernos EBAPE do Vol. IX, no. 3 (2011), sendo uma edição especial: "Gestão Social: Ensino, Pesquisa e Prática". Na sequência, esses trabalhos foram analisados levando em consideração as ecologias apontadas por Boaventura Santos: ecologia dos saberes, das temporalidades, do reconhecimento, das escalas locais e globais e das produtividades.

O primeiro artigo analisado intitula-se "Gestão Social: Reflexões Teóricas e Conceituais", de Airton Cardoso Cançado, Fernando Guilherme Tenório e José Roberto Pereira, publicado no Cadernos EBAPE em 2011. Nesse artigo, os autores tiveram por objetivo apresentar os avanços e as críticas em relação à Gestão Social e propor uma delimitação inicial para esse campo em construção. Para tanto, optaram por um ensaio teórico, levando em consideração os aportes teóricos e também as principais críticas e contribuições para o campo.

Os autores do artigo em análise são apontados como principais referências teóricas sobre a temática no Brasil. A maior preocupação deles é com a vulgarização do tema nas teorias difundidas e também nas comunidades de práticas. Dessa forma, o artigo resgata reflexões de outros teóricos acerca da Gestão Social, pois reconhecem que ainda não há um esgotamento conceitual da Gestão Social. Assim, Cançado et al. reconhecem o campo em uma fase de construção, mas o delimitam como uma alternativa teórica e prática ao pensamento organizacional hegemônico.

Ao analisar esse artigo, observa-se que se trata de um trabalho cujo objeto está dentro do que Boaventura Santos chamou de sociologia das ausências e sociologia das emergências. A Gestão Social vislumbra-se como um modo alternativo de conhecimento e de práticas sociais marginalizadas porque ocupa um lugar de "não existência", na perspectiva da lógica hegemônica. A Gestão Social, da forma que foi apresentada no artigo analisado, está permeada por uma série de ecologias proposta por Boaventura Santos, dentre as quais destacam-se a ecologia dos saberes, a ecologia das transescalas, a ecologia do reconhecimento e ecologia das produtividades. A evidência dessas ecologias está registrada no texto analisado, quando os autores afirmam que a gestão social é antitética à gestão estratégica, uma vez que a sua preocupação é com o envolvimento de todos nos processos de tomada de decisão. Essa percepção permite a identificação de outros saberes, além de ignorar as hierarquias estabelecidas no conflito de classes no interior das organizações e da sociedade.

O segundo artigo analisado intitula-se "Economia Solidaria, Cooperativismo y Sescentralización: la gestíon social puesta en práctica", de Pablo Monje-Reyes. O autor expõe que o objetivo do artigo é discutir conceitualmente sobre a economia solidária, a descentralização e a cooperação nos termos da Gestão Social.

O foco do trabalho está sob novas formas organizacionais que surgiram a partir das crises periódicas do modelo hegemônico. 
São, por exemplo, empresas recuperadas pelos próprios trabalhadores em diversas áreas de produção, como catadores de material reciclável nas grandes metrópoles. $\mathrm{O}$ desenvolvimento da economia solidária tem sido alimentado pelo surgimento dessas novas formas de gestão, que trazem como principal característica o achatamento no processo de tomada de decisão. Portanto, pretende-se ser igualitária, democrática e adaptável ao ambiente no qual está inserida. Monje-Reyes (2011) posiciona a economia solidária como uma forma de inverter a dominação gananciosa do capitalismo sobrea sociedade e sobre a natureza. É intimamente ligada à democracia participativa na forma de organização produtiva, assim fortalecendo os campos políticos, sociais e econômicos. Para viabilizar esse processo, o autor defende que a perspectiva da Gestão Social atua como articuladora entre as ideias da economia solidária e da descentralização, balizadas pela premissa do bem comum.

Ressalta-se que esse segundo artigo em análise pode ser classificado como aderente à sociologia das ausências e à sociologia das emergências de Boaventura, pois converge com as ideias contidas na ecologia de produtividade proposta pelo autor. Como exemplo disso, encontramos na reflexão crítica do autor que as cooperativas têm possibilitado aos participantes uma efetiva participação no processo decisório, proporcionando maior autonomia e emancipação dos atores envolvidos. Além disso, recupera e valoriza os sistemas alternativos de produção. Essa prática causa estranhamento ao pensamento administrativo hegemônico, o qual foi ocultado pelo capitalismo produtivista.

Ademais, a própria temática - economia solidária -recebe ênfase no trabalho de Boaventura sobre a sociologia das ausências e a sociologia das emergências. Para responder à problemática proposta, Santos (2002) selecionou seis países (Moçambique, África do Sul, Brasil, Colômbia, Portugal e Índia), e sua tese era de que os conflitos entre a globalização hegemônica e a globalização contra-hegemônica são mais intensos nestes países, nos quais se identificaram iniciativas e movimentos em algumas áreas temáticas, dentre elas a economia solidária.

O terceiro artigo analisado intitula-se "Gestão Social dos Territórios da Cidadania: o zoneamento ecológico-econômico como instrumento de gestão do território noroeste de Minas Gerais", de José Roberto Pereira, Patrícia Aparecida Ferreira, Ana Alice Vilas Boas, Elias Rodrigues de Oliveira e Raquel Finamor Cardoso.

Os autores expõem que o objetivo do estudo foi mostrar que os resultados do Zoneamento Ecológico-Econômico (ZEE) constitui um instrumento de Gestão Social para o território da cidadania do noroeste de Minas Gerais. Assim, para Pereira et al. (2011), no âmbito dos estudos organizacionais, os estudos sobre desenvolvimento se restringem ao crescimento econômico. Entretanto, o enfoque territorial tornou-se referência para os estudos sobre desenvolvimento e gestão social, pois rompe com o anacronismo citado ao incorporar outras dimensões tais como as sociais, as políticas, as institucionais e as ambientais. Os autores utilizam como referencial teórico a tese do economista indiano
Amartya Sen (2000) de que o desenvolvimento deve ser pensado e praticado como um processo de expansão das liberdades reais que os cidadãos devem desfrutar. O crescimento econômico, nesse caso, tem sua importância apenas como um dos meios para se alcançar o desenvolvimento sustentável. Assim, esse economista trata da renda apenas como uma das esferas do desenvolvimento que, dentre outras, deve envolver um processo igualitário e democrático.

Nessa pesquisa utilizou-se o ZEE, instrumento de medição que fornece informações para o planejamento e a gestão de políticas de desenvolvimento. Portanto, serve de base para a gestão social do território, em que gestores de políticas públicas, organizações sociais, prefeitos municipais e governo federal e estadual podem identificar a potencialidade social de cada município e criar mecanismos de controle, de transparência pública e de accountability. Isso torna possível a interface entre gestão social e gestão pública, estabelecendo metas e objetivos de curto, médio e longo prazo para o desenvolvimento do território.

Sobre esse artigo, observa-se que a temática insere-se na sociologia das ausências e na sociologia das emergências de Boaventura Santos por se tratar de alternativas para as liberdades individuais, embora seja uma consequência do modo de produção exclusivista do capitalismo. Dessa forma, não se respalda pelas ecologias propostas por Boaventura Santos, uma vez que esse tipo de preocupação demonstra a tentativa de enquadramento do desenvolvimento de territórios na pressão da racionalidade dominante e nas formas de produtividade nos padrões reconhecidos de tempo linear e eficaz. Além disso, esse novo paradigma de desenvolvimento não modificou a dimensão econômica, que entrou em consonância com outras dimensões que envolvem a discussão contemporânea sobre desenvolvimento.

O quarto artigo analisado foi "Gestão Social e Cidadania Deliberativa: a experiência de Ilha Comprida - São Paulo", de Edson Sadao lizuka, Sylmara Lopes Francelino Gonçalves-Dias e Pedro Aguerre.

Os autores relatam que o artigo teve como objetivo discutir a atuação de diferentes atores na gestão social, tendo como foco o processo de cidadania deliberativa. Especificamente, analisou a construção do Programa de Extração de Samambaia Silvestre, que ocorreu no município de Ilha Comprida, no estado de São Paulo. Com isso, visou contribuir para o debate sobre o processo de cidadania deliberativa e apresentou os fundamentos das ideias de Habermas e de Tenório, adotando a conceituação de que cidadania deliberativa "significa que a legitimidade das decisões políticas deve ter origem em processos de discussão, orientados pelos princípios da inclusão, do pluralismo, da igualdade participativa, da autonomia e do bem comum" (TENÓRIO, 2005, p. 105).

Os autores relatam que os extratores de samambaia silvestre desse pequeno município encontravam-se em situação de ilegalidade devido às exigências da legislação ambiental do 
estado de São Paulo. No entanto, com a articulação de atores locais em torno do projeto de legalização e formação da associação dos extratores, essa atividade passou a ser reconhecida e legitimada pelas diferentes instâncias do poder público e pela comunidade local, caracterizando-se como uma prática inovadora em Gestão Social nesse território.

Diante das reflexões realizadas pelos autores nesse estudo, observa-se que se trata de um trabalho que Boaventura Santos chamou de sociologia das ausências e sociologia das emergências. O fluxo de ações e o processo decisório ocorridos no projeto de extração da samambaia silvestre em Ilha Comprida estão permeados por uma série de ecologias propostas por Boaventura Santos, dentre as quais se destacam a ecologia dos saberes, a ecologia das temporalidades, a ecologia dos reconhecimentos, a ecologia das trans-escalas e a ecologia das produtividades. A evidência dessas ecologias é desnudada quando os autores afirmam que houve uma conjugação de diferentes saberes, contando com o apoio do setor público, da universidade e da sociedade civil. Essa dinâmica tornou a gestão fluida e flexível, na qual todos têm iguais oportunidades para opinar nos assuntos apresentados e influir no processo dinâmico. Assim como no primeiro artigo analisado, essa prática é estranha ao pensamento hegemônico.

O quinto artigo analisado,"Gestão Social do Desenvolvimento: a exclusão dos representantes dos empresários? O caso do Programa de Territórios da Cidadania Norte-RJ",é de Felipe Barbosa Zani e Fernando Guilherme Tenório. Os autores apresentam como objetivo de pesquisa analisar as possibilidades de inclusão das entidades representantes dos interesses dos empresários com vistas ao pluralismo no âmbito do Programa Territórios da Cidadania Norte-RJ. A premissa que direcionou o estudo foi o projeto de desenvolvimento que acolhe a gestão social, seu princípio da inclusão - relativo à incorporação dos atores excluídos do processo decisório - e do pluralismo - relativo à multiplicidade de atores na tomada de decisões sobre as políticas públicas: poder público, sociedade civil e mercado (ZANI \& TENÓRIO, 2008).

Para realizar a análise pretendida, os autores utilizaram uma vasta literatura, tanto estrangeira quanto nacional, com a preocupação de delimitar a compreensão teórica sobre as teorias desenvolvimentistas, com a introdução da abordagem territorial, perante a incapacidade do Estado de desempenhar o adequado papel que a ele pertence.

Os autores analisam os programas de desenvolvimento territoriais da cidadania no norte do Rio de Janeiro, especificamente em relação às entidades de representação dos interesses empresariais, e concluem que o modelo de gestão social não conseguiu promover diálogo entre esses diferentes atores. O trabalho analisado não apresentou um tema dentro do campo da sociologia das ausências e da sociologia das emergências definido por Boaventura Santos. Assim, não foi possível verificar as questões das ecologias propostas por Boaventura.
O sexto artigo analisado intitula-se "A Emergência do Paradigma de Desenvolvimento centrado no Território na Observação de duas políticas no Cariri cearense", de Valéria Gianella e Antônio Édio Pinheiro Callou. Nesse artigo, os autores objetivaram uma inserção no vasto debate corrente em torno da temática do Desenvolvimento Territorial e suas implicações no campo da Gestão Social, na tentativa de contribuir para esse campo por meio da observação de duas políticas de desenvolvimento territorial em curso de implementação no Cariri cearense.

Para tanto, optaram por realizar o trabalho com base na observação de duas políticas de desenvolvimento territorial em curso de implementação no Cariri cearense, levando-se em consideração elementos particulares que extrapolam a questão econômica. Os autores concentraram o estado da arte sobre as concepções de desenvolvimento típicas e perceberam que tais teorias não dão conta de superar as crises econômicas, sociais e ambientais. É necessário, portanto, considerar as particularidades de cada território para assim garantir o compromisso com a transformação de contextos sociais de referência.

Gianella e Callou (2011) trazem uma relevante reflexão acerca dos rótulos de países desenvolvidos e subdesenvolvidos. Considerando que tais qualificações são endereçadas independente de qualquer identidade e pertencimento geográfico e cultural e de qualquer análise e interpretação apurada das razões histórico-políticas e sociais que determinaram aquela situação. A crítica dos autores é em torno da visão importada, centralizadora e unívoca do desenvolvimento. Os autores perceberam que nos casos analisados há uma grande discrepância entre a prática e a teoria, e destacam que o desafio central está em estabelecer diálogos entre atores sociais e governo.

Sobre esse artigo, observa-se que a temática se insere na sociologia das ausências e na sociologia das emergências de Boaventura Santos por se tratar de alternativas e reflexões sobre o desenvolvimento territorial, embora seja uma consequência do modo de produção exclusivista do capitalismo. Dessa forma, não se respalda pelas ecologias propostas por Boaventura Santos, uma vez que esse tipo de preocupação parece demonstrar a tentativa de enquadramento do desenvolvimento de territórios na pressão da racionalidade dominante e nas formas de produtividade nos padrões reconhecidos de tempo linear e eficaz. Como exemplo disso, encontra-se na fala dos autores do texto analisado que algumas práticas podem ser remodeladas visando à descentralização e difusão, porém objetivando atingir a homogeneidade e coesão de visão de futuro.

O sétimo artigo analisado,"Desenvolvendo a aprendizagem em gestão social: proposta pedagógica de fomento às incubadoras sociais", é de Luis Moretto Neto, Paulo Otolini Garrido e Carlos Eduardo Justen. Os autores expõem que o objetivo do artigo é delinear uma proposta pedagógica das incubadoras de projetos de gestão social, alicerçada no paradigma paraeconômico de Ramos, na Gestão Social e na 
pedagogia da autopoiese, da alternância do encontro e da cultura do serviço.

Os autores trazem uma reflexão inicial sobre a relevância da educação como meio de potencializar a capacidade reflexiva e deliberativa do ser humano, ou seja, a educação como prática de liberdade. Todavia, em lugar de ser o lócus da práxis da autonomia política humana, a educação acaba sendo praticada sob o crivo da lógica financeira, objetivando adaptar-se às necessidades do capital, atendendo ao desenvolvimento capitalista. Nesse sentido, os autores defendem que a extensão universitária, como forma de construir conhecimentos mediante o contexto local, em relação dialógica,mantém uma aderência com a concepção de Gestão Social. Argumentam ainda que a atividade de extensão pode constituir um local apropriado, permitindo tanto o resgaste da educação e da universidade em relação à sua função social e ao seu aspecto político, quanto o efetivo desenvolvimento local. A proposta pedagógica elaborada pelos autores tratada extensão universitária à luz das proposições de Paulo Freire.

Atualmente, a universidade é responsável pelo curso de graduação em Administração Pública nos polos dos estados de Santa Catarina, Roraima e Bahia. Os autores reconhecem as particularidades das regiões que a UFSC atua no projeto UAB, a saber, desigualdades socioeconômicas, conflitos culturais, ambientais e ideológicos. Todavia, o que se opera nas regiões é a oferta de ensino nos moldes tradicionais, que pouco contribui para a autopromoção e a autossustentação locais. Nesse sentido, os autores inserem a proposta das incubadoras de projetos de Gestão Social a serem desenvolvidas, em caráter piloto, no polo de educação a distância na cidade de Canoinhas, no planalto norte-catarinense.

Ressalta-se que a proposta pedagógica das incubadoras de projetos de Gestão Social pode ser classificada dentro da sociologia das ausências e da sociologia das emergências de Boaventura, pois converge com as ideias contidas nas ecologias propostas pelo autor, nas quais os saberes e os reconhecimentos são múltiplos. Como exemplo disso, encontra-se na descrição da proposta de extensão possibilidades de abrir espaço para segmentos excluídos da sociedade, além de ligar e religar os saberes acadêmico e popular. Essa prática caminha na contramão da lógica instrumental e do pensamento hegemônico.

O oitavo artigo analisado intitula-se "Desenvolvimento territorial sustentável e desafios postos por megaempreendimentos: o caso do município de Itaguaí-RJ",de Jeferson Simões Santana, Cezar Augusto Miranda Guedes e Lamounier Erthal Villela. Os autores expõem que o objetivo do estudo foi avaliar a ação dos poderes públicos locais e da sociedade civil na construção da sustentabilidade territorial, face aos processos de implantação de megaempreendimentos no município de Itaguaí/RJ.

Os autores narram uma série de investimentos realizada por iniciativas públicas e privadas na região do município de Itaguaí/RJ. Todavia, salientam que o poder local do município pouco atua para defender os interesses de sua cidade e de seus cidadãos frente ao estabelecimento de grandes empreendimentos, cujos objetivos, planos e lucros estão distantes, mas as consequências econômicas, físicas e sociais são locais.

Para alcançar o objetivo traçado, os autores investigaram a atuação do poder local frente aos desafios trazidos pelos grandes empreendimentos. Investigaram também a capacidade dos instrumentos disponíveis do poder local para o tratamento técnico e político junto aos interesses e estratégias do poder central e dos capitais envolvidos, principalmente quanto à capacidade de monitorar as ações.

Os autores relatam que não há instrumento de participação que permita aos atores sociais atuarem no desenvolvimento local. Os instrumentos utilizados apenas privilegiam o controle do poder público e dos administradores dos empreendimentos sobre orçamento e planejamento, visando à busca da vantagem comparativa e da viabilidade do lucro.

Apesar de os resultados apresentados pelos autores legitimarem o pensamento administrativo hegemônico, o desenvolvimento da pesquisa e seu objeto permitiram perceber alguns elementos que se enquadram nas ecologias dos saberes, dos reconhecimentos e das trans-escalas de Boaventura. Os autores pretendem dar visibilidade para práticas sociais marginalizadas e descredibilizadas porque ocupam um lugar de "não existência", na perspectiva da lógica hegemônica. Vislumbram-se, no caso analisado, modos alternativos de conhecimento, dando espaço para que os cidadãos possam participar dos processos de tomada de decisão.

O nono artigo analisado foi "Desenvolvimento local e estratégia de pequenos empreendimentos agroindustriais - a lógica da cooperação e do associativismo: o Pacto Fonte Nova", de Jorge Oneide Sausen, Ivete Aparecida Patias e Sérgio Luís Allebrandt. Os autores relatam que o artigo teve como objetivo analisar e compreender o processo de criação e desenvolvimento desse empreendimento e suas relações com o processo de desenvolvimento local e regional.

A análise foi realizada objetivando entender o processo evolutivo de estruturação e mudança do empreendimento Pacto Fonte Nova, localizado em Crissiumal, no estado do Rio Grande do Sul. O empreendimento Pacto Fonte Nova trata-se de uma organização associativa, articulada em torno de um projeto de desenvolvimento local, com origem em um trabalho de cooperação entre o poder público local, as lideranças estratégicas do município e as forças produtivas da localidade.

A exposição do caso em análise empreendida por Sausen, Patias e Allebrandt (2011) permitiu conceber alguns elementos que se enquadram nas ecologias dos saberes e dos reconhecimentos de Boaventura, conforme demonstrado na passagem que segue:

As estratégias empregadas direcionavam-se inicialmente a alternativas para uma faixa da população mais marginalizada, os pequenos produtores rurais, no caso. 
Os idealizadores do programa sempre primaram pela participação ativa de todos os envolvidos, principalmente das entidades promotoras e dos agroindustriários, demonstrando uma forma cooperada de trabalhar (SAUSEN, PATIAS e ALLEBRANDT, 2011, p. 890)

Esse empreendimento contou com o apoio do poder público para sua realização, denotando uma preocupação para além do desenvolvimento econômico com as dimensões social, cultural, ambiental e físico-cultural, político-institucional e científicotecnológica, coadunando com as ideias de desenvolvimento local trazidas pela Gestão Social (TENÓRIO, 2007).

Parte-se do princípio da ideia da superação de uma concepção de gestão que tem dado ênfase somente na busca da eficiência e da eficácia organizacionais. A exagerada ênfase nesses conceitos tem restringido a consecução de objetivos ao desenvolvimento num sentido mais amplo. Agrega-se, na análise deste estudo, 0 conceito de efetividade organizacional, que significa 0 alcance de objetivos do desenvolvimento econômicosocial (p. 870).

Essa preocupação parece demonstrar uma tentativa de enquadramento em um sistema alternativo de produção, diferente daqueles que o capitalismo produtivista ocultou.

O décimo artigo analisado,"A inclusão de catadores em programas de coleta seletiva: da agenda local à nacional",é de Maria Cecília Gomes Pereira e Marco Antonio Carvalho Teixeira. Os autores apresentam como objetivo de pesquisa discutir como a inclusão social e produtiva de catadores de materiais recicláveis, antes presente apenas na agenda de políticas públicas locais, alcançou a agenda governamental nacional.

Os autores traçam na pesquisa toda a trajetória da formação associativa de catadores no Brasil até o momento em que o tema ganhou repercussão pública, ocupou espaço na agenda de governos locais, desde 2003, no governo Lula, e alcançou a agenda governamental nacional. Cumpre salientar que esse processo não se deu de maneira linear e simples, mas foi marcado por dinâmicas variadas e conflitos sociais.

Esse artigo apresenta um tema que é latente na sociologia das emergências e na sociologia das ausências de Boaventura de Sousa Santos: o cooperativismo e a autogestão. Ademais, existe um grande potencial para a inversão da lógica capitalista presente nas ações permeadas pela Gestão Social nessa temática. Contudo, na descrição e análise do caso, não foi possível, com os dados disponíveis, verificar as questões das ecologias propostas por Boaventura, pois a abordagem teórica adotada, o modelo de Múltiplos Fluxos, de Kingdon, não conseguiu abarcar as questões da realidade investigada e tampouco apresentar o dialogismo entre o poder público e a sociedade civil. Dessa forma, não foi possível assinalar rupturas ou tentativas destes nas lógicas da monocultura do saber e do rigor científico, da classificação social, da escala global ou do produtivista.
Finalmente, o décimo primeiro artigo analisado foi "Gestão social e cidadania deliberativa: uma análise da experiência dos Coredes no Rio Grande do Sul, 1990-2010", de Sérgio Luis Allebrandt, Dieter Rugard Siedenberg, Jorge Oneide Sausen e Cristiele Tomm Deckert. Os autores esclarecem que o objetivo do estudo é analisar entendimentos, intencionalidades e formas de agir praticadas pelos Coredes na gestão do processo de desenvolvimento local e regional e no fortalecimento da cidadania.

O artigo analisado aborda a prática da Gestão Social nos Conselhos Regionais de Desenvolvimento (Coredes) e analisam a experiência no Rio Grande do Sul ao longo dos últimos 20 anos. Contudo, os autores salientam que os espaços públicos para discussão criados pelos Conselhos Regionais de Desenvolvimento (Coredes), no Rio Grande do Sul, pelos Fóruns de Desenvolvimento Regional (FDRs), em Santa Catarina, e pelos Conselhos Regionais de Desenvolvimento Sustentável (CRDS), no Ceará, ainda parecem ser uma concepção ideal distante da prática generalizada, que utiliza o discurso da participação muito mais como fonte legitimadora de poder e de repasse de recursos no processo de descentralização.

Dessa forma, a pesquisa buscou identificar as formas e o significado de participação cidadã nas decisões do poder público. Para tanto, os autores utilizaram a matriz de categorias e subcategorias de análise, que contempla os princípios da inclusão, do pluralismo, da igualdade participativa, da autonomia e do bem comum, presentes no conceito de cidadania deliberativa de Tenório (2007). A democracia deliberativa é entendida como um modelo político decisório que pauta-se em relações dialógicas entre os participantes. Os autores afirmam que se trata de um processo dialógico que necessita ser construído e reconstruído permanentemente pelos participantes a fim de evitar a cooptação e a manipulação ainda presentes nas incipientes experiências de Gestão Social.

Nesse trabalho, assim como em outros analisados, os autores perceberam que nos casos analisados há uma grande discrepância entre a prática e a teoria, e destacam que o desafio central está em estabelecer diálogos entre os atores sociais e o governo. Nesse sentido, observa-se que a temática se insere na sociologia das ausências e sociologia das emergências de Boaventura Santos por se tratar de alternativas e reflexões sobre o desenvolvimento territorial. Contudo, a prática não se respalda pelas ecologias propostas por Boaventura Santos, uma vez que esse tipo de preocupação parece demonstrar a tentativa de enquadramento do desenvolvimento de territórios na pressão da racionalidade dominante e nas formas de produtividade nos padrões reconhecidos de tempo linear e eficaz.

No Quadro 1 está esquematizado uma síntese sobre as análises realizadas anteriormente. 
Quadro 1 - Síntese das análises

\begin{tabular}{|c|c|c|c|c|}
\hline & Título do artigo & Autores & $\begin{array}{c}\text { Apresenta a } \\
\text { perspectiva da } \\
\text { Sociologia das } \\
\text { Ausências e da } \\
\text { Sociologia das } \\
\text { Emergências? }\end{array}$ & $\begin{array}{l}\text { Há elementos das ecologias? } \\
\text { Quais? }\end{array}$ \\
\hline 1 & $\begin{array}{l}\text { Gestão Social: Reflexões } \\
\text { Teóricas e Conceituais. }\end{array}$ & $\begin{array}{c}\text { Airton Cardoso } \\
\text { Cançado, Fernando } \\
\text { Guilherme Tenório e } \\
\text { José Roberto } \\
\text { Pereira. }\end{array}$ & Sim & $\begin{array}{l}\text { - Ecologia dos saberes; } \\
\text { - Ecologia das trans-escalas; } \\
\text { - Ecologia do reconhecimento;e } \\
\text { - Ecologia das produtividades. }\end{array}$ \\
\hline 2 & $\begin{array}{c}\text { Economia Solidaria, } \\
\text { Cooperativismo y } \\
\text { Sescentralización: la gestíon } \\
\text { social puesta en práctica. }\end{array}$ & Pablo Monje-Reyes. & Sim & Ecologia de produtividade. \\
\hline 3 & $\begin{array}{c}\text { Gestão Social dos Territórios da } \\
\text { Cidadania: o zoneamento } \\
\text { ecológico-econômico como } \\
\text { instrumento de gestão do } \\
\text { território noroeste de Minas } \\
\text { Gerais. }\end{array}$ & $\begin{array}{c}\text { José Roberto } \\
\text { Pereira, Patrícia } \\
\text { Aparecida Ferreira, } \\
\text { Ana Alice Vilas } \\
\text { Boas, Elias } \\
\text { Rodrigues de } \\
\text { Oliveira e Raquel } \\
\text { Finamor Cardoso. }\end{array}$ & Sim & Não se respalda pelas ecologias. \\
\hline 4 & $\begin{array}{c}\text { Gestão Social e Cidadania } \\
\text { Deliberativa: a experiência de Ilha } \\
\text { Comprida - São Paulo. }\end{array}$ & $\begin{array}{l}\text { Edson Sadaolizuka, } \\
\text { Sylmara Lopes } \\
\text { Francelino } \\
\text { Gonçalves-Dias e } \\
\text { Pedro Aguerre. }\end{array}$ & Sim & $\begin{array}{l}\text { - Ecologia dos saberes; } \\
\text { - Ecologia das temporalidades; } \\
\text {-Ecologia dos reconhecimentos; - } \\
\text { Ecologia das trans-escalas; e } \\
\text { - Ecologia das produtividades. }\end{array}$ \\
\hline 5 & $\begin{array}{c}\text { Gestão Social do } \\
\text { Desenvolvimento: a exclusão dos } \\
\text { representantes dos empresários? } \\
\text { O caso do Programa de } \\
\text { Territórios da Cidadania Norte- } \\
\text { RJ. } \\
\end{array}$ & $\begin{array}{l}\text { Felipe Barbosa Zani } \\
\text { e Fernando } \\
\text { Guilherme Tenório. }\end{array}$ & Não & 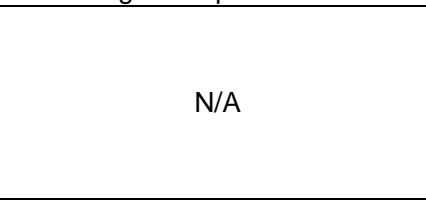 \\
\hline 6 & $\begin{array}{l}\text { A Emergência do Paradigma de } \\
\text { Desenvolvimento centrado no } \\
\text { Território na Observação de duas } \\
\text { políticas no Cariri cearense. }\end{array}$ & $\begin{array}{l}\text { Valéria Gianella e } \\
\text { Antônio Édio } \\
\text { Pinheiro Callou. }\end{array}$ & Sim & Não se respalda pelas ecologias. \\
\hline 7 & $\begin{array}{c}\text { Desenvolvendo a aprendizagem } \\
\text { em gestão social: proposta } \\
\text { pedagógica de fomento às } \\
\text { incubadoras sociais. }\end{array}$ & $\begin{array}{l}\text { Luis Moretto Neto, } \\
\text { Paulo Otolini } \\
\text { Garrido e Carlos } \\
\text { Eduardo Justen. }\end{array}$ & Sim & $\begin{array}{l}\text { - Ecologia dos saberes; e } \\
\text {-Ecologia dos reconhecimentos. }\end{array}$ \\
\hline 8 & $\begin{array}{l}\text { Desenvolvimento territorial } \\
\text { sustentável e desafios postos por } \\
\text { megaempreendimentos: o caso } \\
\text { do município de Itaguaí-RJ. }\end{array}$ & $\begin{array}{c}\text { Jeferson Simões } \\
\text { Santana, Cezar } \\
\text { Augusto Miranda } \\
\text { Guedes e } \\
\text { LamounierErthal } \\
\text { Villela. } \\
\end{array}$ & Sim & $\begin{array}{l}\text { - Ecologia dos saberes; } \\
\text { - Ecologia dos reconhecimentos; } \\
\text { - Ecologia das trans-escalas. }\end{array}$ \\
\hline 9 & $\begin{array}{c}\text { Desenvolvimento local e } \\
\text { estratégia de pequenos } \\
\text { empreendimentos agroindustriais } \\
\text { - a lógica da cooperação e do } \\
\text { associativismo: o Pacto Fonte } \\
\text { Nova. } \\
\end{array}$ & $\begin{array}{c}\text { Jorge } \\
\text { OneideSausen, } \\
\text { Ivete Aparecida } \\
\text { Patias e Sérgio Luís } \\
\text { Allebrandt. }\end{array}$ & Sim & $\begin{array}{l}\text { - Ecologia dos saberes; e } \\
\text {-Ecologia dos reconhecimentos }\end{array}$ \\
\hline 10 & $\begin{array}{l}\text { A inclusão de catadores em } \\
\text { programas de coleta seletiva: da } \\
\text { agenda local à nacional. }\end{array}$ & $\begin{array}{c}\text { Maria Cecília } \\
\text { Gomes Pereira e } \\
\text { Marco Antonio } \\
\text { Carvalho Teixeira. } \\
\end{array}$ & Sim & $\begin{array}{c}\text { Não foi possível, com os dados } \\
\text { disponíveis, verificar as questões } \\
\text { das ecologias. }\end{array}$ \\
\hline 11 & $\begin{array}{c}\text { Gestão social e cidadania } \\
\text { deliberativa: uma análise da } \\
\text { experiência dos Coredes no Rio } \\
\text { Grande do Sul, 1990-2010. }\end{array}$ & $\begin{array}{c}\text { Sérgio } \\
\text { LuisAllebrandt, } \\
\text { DieterRugardSieden } \\
\text { berg, Jorge } \\
\text { OneideSausen e } \\
\text { CristieleTommDecke } \\
\text { rt. } \\
\end{array}$ & Sim & Não se respalda pelas ecologias. \\
\hline
\end{tabular}


Dos onze artigos analisados, demonstra-se que seis deles se enquadram nas ecologias de Boaventura, sendo que dois artigos tratam de uma reflexão teórica na qual a Gestão Social vislumbrase como um modo alternativo de conhecimento e de práticas sociais marginalizadas, na perspectiva da lógica hegemônica. Desse modo, o arcabouço teórico no qual a Gestão Social se ampara alinha-se com a sociologia das ausências e sociologia das emergências, e consequentemente com as ecologias de Boaventura de Sousa Santos. Em quatro dos casos analisados, observa-se algumas práticas de gestão que lembram as ecologias de Boaventura, como o fluxo de ações e o processo decisório. Essa dinâmica tornou a gestão fluida e flexível, na qual todos têm iguais oportunidades para opinar nos assuntos apresentados e influir no processo dinâmico.

Três dos artigos analisados tratam de temáticas que precisam ganhar visibilidade, como o desenvolvimento local e a sustentabilidade, porém as práticas sociais respondem às lógicas do modelo racional do ocidente, de uma razão indolente. Percebese que a lógica mercantil permanece nas tentativas de enquadramento do desenvolvimento de territórios na pressão da racionalidade dominante e nas formas de produtividade nos padrões reconhecidos de tempo linear e eficaz.

Em dois artigos analisados não foi possível identificar as ecologias nos dados apresentados. Os autores utilizaram de modelos teóricos que não favoreceram atingir o objetivo de pesquisa traçado. Desse modo, não foi possível a observância das ecologias defendidas por Boaventura nas práticas sociais.

Diante do exposto, conclui-se com esta pesquisa que a Gestão Social, como uma nova possibilidade de gestão que se apresenta, está alinhada com as ausências e emergências de Boaventura Santos. Ademais, o fato de encontrarmos espaços para a disseminação dessa lógica em um periódico de reconhecimento nacional em Administração denota a importância do tema e as possibilidades de interlocução com temas não dominantes nas ciências administrativas.

Nesse sentido, a pesquisa realizada demonstra uma grande lacuna entre a teoria proposta pela Gestão Social e as práticas encontradas em diferentes partes do Brasil, o que exige ainda um grande esforço teórico para encurtar essas distâncias, para assim dar mais visibilidade às alternativas que lutam contra a exclusão e a discriminação oriundas do capitalismo global e da globalização neoliberal.

Além disso, é importante evidenciar que, apesar do avanço na produção do conhecimento do campo da Gestão Social, ainda não se tem uma visão crítica consolidada e uma definição sólida do referido campo, evidenciando a fragilidade do tema, que ainda precisa de aprofundamento em termos teóricos e metodológicos necessários para o seu fortalecimento. Aqui, a nossa proposta é utilizar as contribuições de Boaventura sobre esse campo afim de ampliarmos esse olhar crítico e não incorremos no equívoco de uma transposição da noção de profissionalização gerencial em um campo que homenageie a busca pela emancipação humana nas organizações.

Nessa linha de reflexão, sugere-se o desenvolvimento de outras pesquisas para investigar outras revistas científicas da área de Administração ou mesmo outros volumes do periódico nacional Cadernos EBAPE objetivando alcançar uma maior representatividade e fornecer um diagnóstico mais amplo da produção na área. Portanto, os pesquisadores reconhecem a limitação dos resultados dessa pesquisa em função da escolha de um único dossiê, que não podem ser extrapoladas.

\section{Referências bibliográficas}

Allebrandt, S. L., Siedenberg, D. R., Sausen, J. O., Deckert, C. T. (2011, setembro). Gestão social e cidadania deliberativa: uma análise da experiência dos Coredes no Rio Grande do Sul, 1990-2010. Cadernos EBAPE.BR., 3(9), p. 914-945.

Araújo, E. T. (2012). (In) Consistências da Gestão Social e seus processos de formação: um campo em construção(Tese de Doutorado). Universidade Católica de São Paulo, São Paulo, SP, Brasil.

Caldas, M. P; Cunha, M. P. (2005, jul./set). Ecologistas organizacionais: o paradigma funcionalista em expansão no final do século XX. Revista de Administração de Empresas, 45(3), p. 65-69.

Caldas, M. P; Fachin, R. (2005,abr./jun.). Paradigma funcionalista: desenvolvimento de teorias e institucionalismo nos anos 1980 e 1990. Revista de Administração de Empresas,45(2), p. 46-51.

Cançado, A. C. (2011). Fundamentos teóricos da gestão social (Tese de Doutorado). Universidade Federal de Lavras, Lavras, MG, Brasil

Cançado, A. C., Tenório F. G., Pereira, J. R. (2011, setembro). Gestão social: reflexões teóricas e conceituais. Cadernos EBAPE.BR., 3(9), p. 681703.

Carrion, Rosinha da Silva Machado; Calou, Ângela. (2008). Pensar a Gestão Social em terras de 'Padinho Cícero' (Prefácio). In: Silva Jr, Jeová Torres; Mâish, Rogério Teixeira; Cançado, Airton Cardoso. Gestão Social: Práticas em debate, teorias em construção. Fortaleza: Imprensa Universitária.

França Filho, Genauto Carvalho de. (2008). Definindo Gestão Social. In SILVA JR., Jeová Torres; MÂISH, Rogério Teixeira; CANÇADO, Airton Cardoso. Gestão Social: Práticas em debate, teorias em construção. Fortaleza: Imprensa Universitária.

Giannella, V., Callou, A. E. P. (2011, setembro). A emergência do paradigma de desenvolvimento centrado no território na observação de duas políticas no Cariri cearense. Cadernos EBAPE.BR., 3(9), p. 803-827.

lizuka, E. S., Goncalves-Dias, S. L. F., Aguerre, P. (2011, setembro). Gestão social e cidadania deliberativa: a experiência de Ilha Comprida São Paulo. Cadernos EBAPE.BR., 3(9), p. 774-779.

Japiassu, Hilton. (1991). Alguns instrumentos conceituais; O que é a epistemologia ?, in Introdução ao pensamento epistemológico. Rio de Janeiro: Francisco Alves.

Monje-Reyes, P. (2011, setembro). Economía solidaria, cooperativismo y descentralización: la gestión social puesta en práctica. Cadernos EBAPE.BR., 3(9), p. 704-723.

Neto, L. M., Garrido, P. O., Justen, C. E. (2011, setembro). Desenvolvendo 0 aprendizado em gestão social: proposta pedagógica de fomento às incubadoras sociais. Cadernos EBAPE.BR., 3(9), p. 828-845.

Paes De Paula, A. P. (2005). Por uma nova gestão pública. São Paulo: FGV.

Pereira, J. R., Ferreira, P. A., Vilas Boas, A. A., Oliveira, E. R. de, CARDOSO, R. F. (2011, setembro). Gestão social dos territórios da cidadania: o zoneamento ecológico-econômico como instrumento de gestão do território noroeste de Minas Gerais. Cadernos EBAPE.BR., 3(9), p. 736747.

PEREIRA, M. C. G., Teixeira, M. A. C. (2011, setembro). A inclusão de catadores em programas de coleta seletiva: da agenda local à nacional. Cadernos EBAPE.BR., 3(9), p. 895-913.

Correspondência/Correspondence: Raphaela Reis Conceicao Castro Silva. Universidade Federal de Santa Catarina. R. Eng. Agronômico Andrei Cristian Ferreira, s/n - Trindade, Florianópolis - SC, 88040-900 castroreis@gmail.com 
Ramos, A. G. (1989). A nova ciência das organizações: uma reconceituação da riqueza das nações. 2.ed., Rio de Janeiro: FGV.

Santana, J. S., Guedes, C. A. M., Villela, L. E. (2011, setembro). Desenvolvimento territorial sustentável e desafios postos por megaempreendimentos: o caso do município de Itaguaí - RJ. Cadernos EBAPE.BR., 3(9), p. 846-867.

SANTOS, Boaventura de Sousa (2002). Para uma sociologia das ausências e uma sociologia das emergências, Revista Crítica de Ciências Sociais, 63, 237-280.

Sausen, J. O., Patias, I. A., Allebrandt, S. L. (2011, setembro). Desenvolvimento local e estratégia de pequenos empreendimentos agroindustriais - a lógica da cooperação e do associativismo: o Pacto Fonte Nova. Cadernos EBAPE.BR., 3(9), p. 868-894.
Tenório, F. G. (1998, set./out.). Gestão social: uma perspectiva conceitual. Revista de Administração Pública, Rio de Janeiro, 32(5), p. 7-23.

Tenório, F. G. (2008). Tem razão a administração? 3. ed. ljuí: Editora da Unijuí.

Vergara, S. C.; Caldas, M. P. (2005, out./dez). Paradigma Interpretacionista: a busca da superação do objetivismo funcionalista nos anos 1980 e 1990. Revista de Administração de Empresas, 45(4), p. 66-71.

Zani, F. B., Tenório, F. G. (2011, setembro). Gestão social do desenvolvimento: a exclusão dos representantes dos empresários? $O$ caso do Programa Territórios da Cidadania Norte-RJ. Cadernos EBAPE.BR. 3(9),

$p$

783-802. 